\title{
DISTRIBUTION AND BIOTYPIC COMPOSITION OF THE ARGENTINE STEM WEEVIL PARASITOID IN HAWKE'S BAY
}

\author{
C.B. PHILLIPS ${ }^{1}$, I.I. ILINE ${ }^{1}$, M.W.A. SLAY ${ }^{2}$, M.R. MCNEILL ${ }^{1}$ and \\ R.P. CANE ${ }^{3}$ \\ ${ }^{1}$ AgResearch Ltd, PO Box 60, Gerald St, Lincoln \\ ${ }^{2}$ Homelea Ltd, Shanley Road, RD 9, Hastings \\ ${ }^{3}$ New Zealand Biosecure, 19 Carnegie Road, PO Box 650, Napier \\ Corresponding author: craig.phillips@agresearch.co.nz
}

\begin{abstract}
The Argentine stem weevil parasitoid, Microctonus hyperodae Loan (Hymenoptera: Braconidae), was first released in Hawke's Bay at two locations in 1995. In 2000, eight Hawke's Bay sites situated up to ca $55 \mathrm{~km}$ from the original release sites were surveyed to determine the presence of $M$. hyperodae. The parasitoid was recovered from all eight sites, with the proportion of weevils parasitised at each site ranging from $1 \%$ to $44 \%$. Although parasitoids originating from east and west of the South American Andes mountains had been introduced to both Hawke's Bay release locations in 1995, genetic markers based on variation in malate dehydrogenase allozymes showed that eastern parasitoids predominated at all of the sites sampled in 2000, with western parasitoids occurring in low numbers at only three sites. These results are compared with previous results from other New Zealand locations and their implications discussed. Keywords: Listronotus bonariensis, Curculionidae, biological control, allozyme marker, intraspecific variation.
\end{abstract}

\section{INTRODUCTION}

Argentine stem weevil, Listronotus bonariensis (Kuschel) (Coleoptera: Curculionidae), was discovered in New Zealand in 1927 (Marshall 1937) where it has become a well known pest of pasture grasses and other graminaceous crops. In Hawke's Bay, L. bonariensis larvae can severely curtail establishment of sweet corn crops by transferring from pasture remnants to sweet corn seedlings. Estimated plant population loss in one crop in November 2000 was 30\% (M. Slay, pers. obs.). Though insecticides can be effective, they are not an option for the increasing number of growers using organic production methods. The South American endoparasitoid Microctonus hyperodae Loan (Hymenoptera: Braconidae) was identified as having potential for biological control of L. bonariensis (Loan \& Lloyd 1974) and it has since been established throughout New Zealand (Goldson et al. 1998). It was released at two Hawke's Bay sites in 1995 (McNeill et al. 2002).

New Zealand's founding populations of $M$. hyperodae were collected from eight disparate locations in four South American countries (Goldson et al. 1990). These were Brazil (Porto Alegre), Argentina (Ascasubi, S. C. de Bariloche, and General Roca, Mendoza), Chile (La Serena and Concepcion) and Uruguay (Colonia). Parasitoids from each geographic population were released in equal numbers at each New Zealand location to provide the populations with equal chances of establishing. It was postulated that the South American populations best suited to the conditions encountered at each New Zealand release locality would establish there. The asexual reproduction of $M$. hyperodae (Loan \& Lloyd 1974) has precluded interbreeding between the South American 
populations in New Zealand. Furthermore, inheritance patterns of allozyme markers suggest that the parthenogenetic reproduction of $M$. hyperodae occurs without meiosis and the associated crossing over between homologous chromosomes (Iline \& Phillips 2004). Microctonus hyperodae daughters appear, therefore, to be genetically identical to their mothers, except when new mutations arise. Morphometric (Phillips \& Baird 1996), allozyme (Iline \& Phillips 2004) and PCR-based research (L. Winder, pers. comm.) have shown that the eight $M$. hyperodae geographic populations comprise two main biotypes (genetically differentiated populations), with one originating from east of the South American Andes mountains (EA) and the other from west of the Andes in Chile (WA).

These two M. hyperodae biotypes were released together in the ratio $0.67 \mathrm{EA}: 0.33 \mathrm{WA}$ in Hawke's Bay. If the two biotypes had been equally successful at establishing and reproducing in Hawke's Bay, they should thereafter have remained present in this ratio. This contribution describes a survey conducted in 2000 to measure the distribution of $M$. hyperodae in Hawke's Bay, and to test the null hypothesis that the two biotypes have been equally successful there.

\section{METHODS}

Parasitoids were released on 31 March 1995 near site 6, and 2 April 1995 near site 4 (Fig. 1). On 25 May 1996, an initial assessment of the parasitoid's establishment was made by collecting L. bonariensis adults from both release sites using a leaf-blower with a net fixed to the intake pipe. In 2000, additional weevils were collected from pasture at eight sites (Fig. 1) between 5 September and 12 September using either a leafblower or a sweep net. Parasitism was measured by maintaining all of the weevils from each collection site in separate parasitoid emergence cages for approximately one month at $20^{\circ} \mathrm{C}$ and $15: 9 \mathrm{~h}$ light:dark. The weevils were provided with fresh bouquets of ryegrass every three days. The emergence cages consisted of transparent, polycarbonate containers divided into upper and lower chambers; the upper chambers were fitted with plastic mesh floors. Larval parasitoids present in the weevils developed to the fifth instar, emerged from the weevils, dropped through the mesh floor and pupated under strips of paper towel in the lower chamber. For each collection site, the proportion of weevils that was parasitised was calculated by dividing the number of pre-pupal parasitoids that emerged by the number of weevils collected (only one parasitoid can emerge from a weevil). Adult parasitoids were examined with a microscope to separate $M$. hyperodae from Microctonus aethiopoides Loan (Hymenoptera: Braconidae), which occasionally also parasitises L. bonariensis (McNeill et al. 1993).

A malate dehydrogenase (MDH, E.C. 1.1.1.37) allozyme marker was used to classify parasitoid adults as belonging to either the EA or WA biotype, following the methods of Iline \& Phillips (2004). EA M. hyperodae exhibit only MDH heterozygotes $(M d h-A B)$, while WA $M$. hyperodae exhibit only MDH homozygotes $(M d h-A A)$. Frozen whole insects were ground in 1-3 drops of $0.06 \mathrm{M}$ Tris- $\mathrm{HCl}$ buffer, $\mathrm{pH} 6.8$, containing $10-15 \%$ sucrose, and then centrifuged at 13,000 rpm for $5 \mathrm{~min}$. Vertical polyacrylamide electrophoresis (6-10\% acrylamide gels) was conducted on the protein extracts in an Ornstein-Davis discontinuous system (Rothe 1994). The histochemical stain was that of Murphy et al. (1996), except MTT was replaced with NBT, and $1 \mathrm{mg}$ of PMS was added per $50 \mathrm{ml}$ of staining solution.

The counts of $M$. hyperodae specimens classified as either EA or WA were analysed by calculating chi-square statistics to test the goodness-of-fit between the observed values and those expected under the null hypothesis that the $M$. hyperodae biotypes would occur in the ratio $0.67 \mathrm{EA}: 0.33 \mathrm{WA}$. 


\section{RESULTS}

In 1996, 147 M. hyperodae were reared from 410 L. bonariensis collected at site 6 (36\% parasitism), and 207 M. hyperodae were reared from 500 weevils (41\% parasitism) collected from the release location situated near site 4 (Fig. 1).

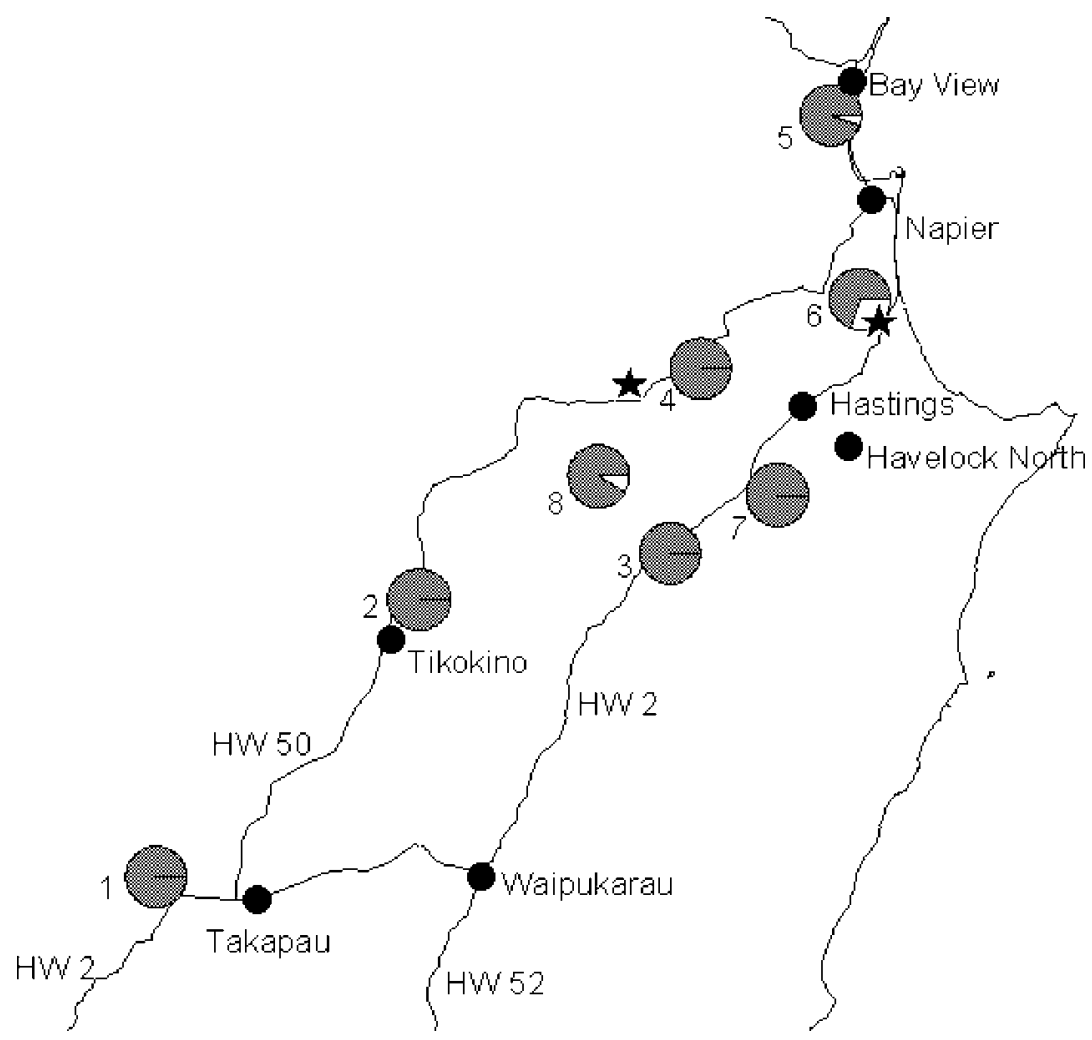

FIGURE 1: Hawke's Bay locations where sampling was conducted in 2000. Pie graphs show relative proportions of the EA (grey) and WA (white) biotypes of Microctonus hyperodae, and stars show the 1995 release locations.

In 2000, M. hyperodae was recovered from all eight sampling sites (Fig. 1). Table 1 shows the number of $L$. bonariensis collected and the percentage that was parasitised at each site. All parasitism was due to $M$. hyperodae except at site 8 where two $M$. aethiopoides were also collected. The proportion of L. bonariensis that was parasitised averaged $19 \%$, and ranged from $1 \%$ at site 1 to $44 \%$ at site 7 (Fig. 1).

Table 1 also shows the number of $M$. hyperodae scored for MDH and the proportions of EA and WA $M$. hyperodae observed at each site. The WA biotype was absent from sites 1, 2, 3, 4 and 7 (Fig. 1). At sites 2, 3, 4 and 7, the proportion of EA M. hyperodae 
TABLE 1: Parasitism (\%) of L. bonariensis by EA and WA M. hyperodae and ratio of EA:WA M. hyperodae at eight Hawke's Bay sites in 2000.

\begin{tabular}{lcccccc}
\hline Site & $\begin{array}{c}\text { No. of } \\
\text { L. bonariensis }\end{array}$ & $\begin{array}{c}\text { Percent } \\
\text { parasitism }\end{array}$ & $\begin{array}{c}\text { No. M. hyperodae } \\
\text { scored for MDH }\end{array}$ & EA: WA & $\begin{array}{c}X^{2} \\
(1 \mathrm{df})\end{array}$ & P-value \\
\hline 1 & 166 & 1 & 1 & $1: 0$ & - & - \\
2 & 175 & 22 & 20 & $1: 0$ & 9.85 & $<0.005$ \\
3 & 168 & 35 & 20 & $1: 0$ & 9.85 & $<0.005$ \\
4 & 372 & 8 & 20 & $1: 0$ & 9.85 & $<0.005$ \\
5 & 195 & 12 & 20 & $0.95: 0.05$ & 7.09 & $<0.01$ \\
6 & 233 & 18 & 20 & $0.7: 0.3$ & 0.08 & $>0.75$ \\
7 & 336 & 44 & 19 & $1: 0$ & 9.36 & $<0.005$ \\
8 & 237 & 9 & 12 & $0.92: 0.08$ & 3.3 & $>0.05$ \\
\hline
\end{tabular}

${ }^{1}$ Includes two M. aethiopoides

was significantly greater than expected under the null hypothesis of equal competitiveness between the two biotypes (Table 1). No chi-square test was conducted for site 1, since it yielded only one $M$. hyperodae specimen. Of the three sites where WA $M$. hyperodae was found, the proportions of EA and WA $M$. hyperodae observed at sites 6 and 8 were not significantly different to those expected under the null hypothesis, but significantly more EA $M$. hyperodae than expected were found at site 5 (Table 1).

\section{DISCUSSION}

The results confirmed that $M$. hyperodae has established throughout much of Hawke's Bay, although its entire distribution was not delimited by this survey since it was found at all of the sites sampled. Nevertheless, based on observations in Canterbury, it is likely that site 1 (Fig. 1) represented the maximum extent of its dispersal. In Canterbury, $M$. hyperodae spread most quickly to the south west at a rate of ca $3.5 \mathrm{~km}$ per year, probably due to flights of parasitoid adults and parasitised hosts in north easterly sea breezes, and with no evidence of human assisted dispersal (Goldson et al. 1999). Moreover, parasitism rates were found to rapidly decline with increasing distance from the release site (Goldson et al. 1999). Thus, the $1 \%$ parasitism rate at site 1 , which is ca $55 \mathrm{~km}$ south west of the Hawke's Bay release sites (Fig. 1), probably indicates the species had only recently arrived at this site after dispersing at the relatively high rate of ca $11 \mathrm{~km}$ per year, probably also in association with north easterly sea breezes. The apparently greater dispersal rate in Hawke's Bay than in Canterbury could be due to temperature differences between the regions and their associated influences on insect flight activity.

The parasitism rates observed in Hawke's Bay in 2000, which averaged 19\%, were generally lower than expected given the $36 \%$ and $41 \%$ parasitism measured at the release sites in 1996. This was particularly so at site 4, which was within $5 \mathrm{~km}$ of a release site (Fig. 1), but yielded only $8 \%$ parasitism in 2000. In contrast, parasitism reached $74 \%$ four years after M. hyperodae had been released at Lincoln (Goldson et al. 1998). Factors including pasture quality may have influenced parasitism rates since, for example, field data have shown endophytic ryegrass can have a suppressive effect on parasitism of L. bonariensis by M. hyperodae (Goldson et al. 2000). In this case, decreased feeding and oviposition by L. bonariensis on endophytic plants probably reduces opportunities for M. hyperodae females to lay their eggs (Phillips 2002).

The predominance of EA M. hyperodae in Hawke's Bay was generally consistent with previous results from elsewhere in New Zealand, including North Auckland, Waikato, Bay of Plenty, Wairarapa and Otago, where the WA biotype rapidly became very rare after its release (Phillips et al. 1997; C.B. Phillips, unpubl. data). However, the occurrence of significant, small scale, spatial variation in the success of the two biotypes, such as that seen in Hawke's Bay where WA M. hyperodae was present in significant numbers 
at some sites, while apparently being absent from others, has not previously been observed. For example, Wairarapa represents a contrasting situation where only one WA $M$. hyperodae has been found amongst $>550$ specimens collected from $>30$ sites over 3 years (C.B. Phillips, unpubl. data). Research at Lincoln where, unlike other locations, WA $M$. hyperodae became common after 1995, has recently shown that annual variations in the biotypic composition of the parasitoid population have been closely correlated with temperature variations between years (C.B. Phillips, unpublished data). Thus the situation in Hawke's Bay offers the very valuable opportunity to test the effects of microclimatic variations on the success of the two biotypes, both within and between years, to better understand their differing performance characteristics.

Microctonus hyperodae will rapidly spread throughout the remainder of Hawke's Bay and should help to alleviate L. bonariensis damage to ryegrass, sweet corn and other Graminae. However, additional information about the phenology of $M$. hyperodae in Hawke's Bay, the susceptibility of its various life stages to pesticides, and the relationships between $L$. bonariensis densities, parasitism and crop damage is required to enable growers to optimise their management, both of $L$. bonariensis and its biological control agent. Current research which aims to enhance the efficacy of $M$. hyperodae through the provision of floral resources (Phillips et al. 1998; Vattala et al. 2004) could also eventually further improve suppression of L. bonariensis in pastures and crops.

\section{ACKNOWLEDGEMENTS}

The authors are grateful to Paul Phippen, John Hudson, Scott Lawson, Mark Apatu, Tom Couper, Dennis McKenzie, Allan Kittow and Mike Glazebrook for allowing samples to be collected on their properties, and to John Charles (HortResearch, Auckland) for his helpful review of this manuscript. Ilia Iline's contribution to this paper was supported by an AGMARDT post doctoral fellowship.

\section{REFERENCES}

Goldson, S.L.; McNeill, M.R.; Stufkens, M.W.; Proffitt, J.R.; Farrell, J.A. 1990: Importation and quarantine of Microctonus hyperodae, a South American parasitoid of Argentine stem weevil. Proc. 43rd N. Z. Weed and Pest Control Conf.: 334-338.

Goldson, S.L.; Proffitt, J.R.; Baird, D.B. 1998: Establishment and phenology of the parasitoid Microctonus hyperodae (Hymenoptera: Braconidae) in New Zealand. Environ. Entomol. 27: 1386-1392.

Goldson, S.L.; Proffitt, J.R.; Fletcher, L.R.; Baird, D.B. 2000: Multitrophic interaction between the ryegrass host plant, Lolium perenne, its endophyte Neotyphodium lolii, the weevil pest Listronotus bonariensis and its parasitoid Microctonus hyperodae Loan. N. Z. J. Agric. Res. 43: 227-233.

Goldson, S.L.; Proffitt, J.R.; McNeill, M.R.; Baird, D.B. 1999: Linear patterns of dispersal and build up of the introduced parasitoid Microctonus hyperodae (Hymenoptera: Braconidae) in Canterbury, New Zealand. Bull. Entomol. Res. 89: 347-353.

Iline, I.I.; Phillips, C.B. 2004: Allozyme markers to help define the South American origins of Microctonus hyperodae (Hymenoptera: Braconidae) established in New Zealand for biological control of Argentine stem weevil. Bull. Entomol. Res. 94: 229-234.

Loan, C.C.; Lloyd, D.C. 1974: Description and field biology of Microctonus hyperodae Loan n. sp. (Hymenoptera: Braconidae, Euphorinae) a parasite of Hyperodes bonariensis in South America (Coleoptera: Curculionidae). Entomophaga 19(1): 7-12.

Marshall, G.A.K. 1937: New Curculionidae collected from New Zealand. Transactions of the New Zealand Institute 67: 316-340.

McNeill, M.R.; Goldson, S.L.; Proffitt, J.R.; Phillips, C.B.; Addison, P.J. 2002: A description of the commercial rearing and distribution of Microctonus hyperodae (Hymenoptera: Braconidae) for biological control of Listronotus bonariensis (Kuschel) (Coleoptera: Curculionidae). Biol. Control 24: 165-175. 
McNeill, M.R.; Phillips, C.B.; Goldson, S.L. 1993: Diagnostic characteristics and biology of three Microctonus spp. (Hymenoptera: Braconidae, Euphorinae) parasitoids of weevils (Coleoptera: Curculionidae) in New Zealand pasture and lucerne. $N$. Z. Entomol. 16: 39-44.

Murphy, R.W.; Sites, J.W.; Buth, D.G.; Haufler, C.H. 1996: Proteins: Isozyme electrophoresis. In: Hillis, D.M.; Moritz, C.; Mable, B.K. ed. Molecular systematics. Sinauer Associates, Sunderland, MA. Pp. 51-120.

Phillips, C.B. 2002: Observations of oviposition behavior of Microctonus hyperodae Loan and M. aethiopoides Loan (Hymenoptera: Braconidae: Euphorinae). J. Hymenoptera Res. 11: 326-337.

Phillips, C.B.; Baird, D.B. 1996: A morphometric method to assist in defining the South American origins of Microctonus hyperodae Loan (Hymenoptera: Braconidae) established in New Zealand. Biocontrol, Sci. Technol. 6: 189-205.

Phillips, C.B.; Baird, D.B.; Goldson, S.L. 1997: South American origins of Microctonus hyperodae Loan (Hymenoptera: Braconidae) established in New Zealand as defined by morphometric analysis. Biocontrol, Sci. Technol. 7: 247-258.

Phillips, C. B.; Proffitt, J. P.; Goldson, S. L. 1998: Potential to enhance the efficacy of Microctonus hyperodae Loan (Hymenoptera: Braconidae), a parasitoid of Argentine stem weevil. N. Z. Plant Prot. 51: 16-22.

Rothe, G.M. 1994: Electrophoresis of enzymes: Laboratory methods. Springer-Verlag, New York.

Vattala, H.D.; Wratten, S.D.; Phillips, C.B. 2004: Effects of floral nectars on longevity of Microctonus hyperodae, a parasitoid of Listronotus bonariensis adults. Proceedings of the XXII International Congress of Entomology, Brisbane: in press. 